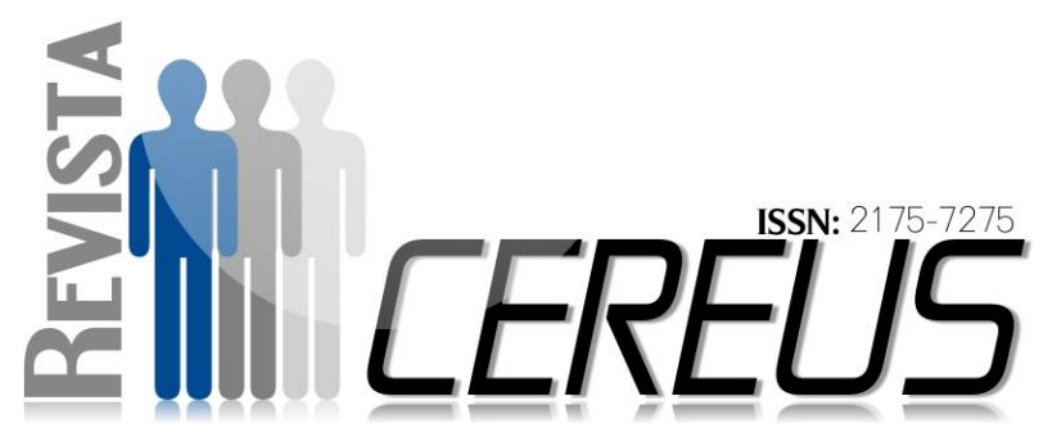

\title{
COMPOSIÇÃO CENTESIMAL E ASPECTOS FÍSICO-QUÍMICOS DOS FRUTOS DA BACABA (OENOCARPUS DISTICHUS MART.)
}

\author{
RIBEIRO, Carliane Lima ${ }^{1}$ \\ LACERDA, Gabriela Eustáquio ${ }^{2}$ \\ PIRES, Caroline Roberta Freitas ${ }^{3}$ \\ NASCIMENTO, Guilherme Nobre Lima do ${ }^{4}$ \\ PEREIRA, Renata Junqueira ${ }^{5}$
}

\section{RESUMO}

As frutas nativas do cerrado, como a bacaba (Oenocarpus distichus Mart.), são apreciadas pelos seus sabores exóticos, entretanto, os aspectos nutricionais da bacaba ainda são pouco conhecidos. Assim, o presente estudo analisou parâmetros de qualidade, aspectos físico-químicos e de composição centesimal da polpa e da amêndoa da bacaba. A

\footnotetext{
${ }^{1}$ Mestre, Instituto Federal do Maranhão, Campus de Açailândia - MA, carlianelima@ifma.edu.br

2 Mestre, Universidade Federal do Tocantins, Campus de Palmas - TO, gabrielaeustaquio@uft.edu.br

${ }^{3}$ Doutora, Universidade Federal do Tocantins, Campus de Palmas - TO, carolinerfpires@mail.uft.edu.br

${ }^{4}$ Doutor, Universidade Federal do Tocantins, Campus de Palmas - TO, guilherme.nobre@uft.edu.br.br

$5^{\star}$ Doutora, Universidade Federal do Tocantins, Campus de Palmas - TO, renatajunqueira@uft.edu.br

* Autora para correspondência: Quadra 109 Norte, Avenida NS15, ALCNO 14, Laboratório de Nutrição, Estação Experimental, Campus Universitário de Palmas, CEP 77001-090
} 
polpa e a amêndoa da $O$. distichus Mart. apresentaram, respectivamente, teores de umidade de 53,72 g.100g-1 e $62,73 \mathrm{~g} .100 \mathrm{~g}-1$; teores de extrato etéreo de $15,21 \mathrm{~g} \cdot 100 \mathrm{~g}-1 \mathrm{e}$ 0,20 g.100g-1; teores de proteínas de 3,8g.100g-1 e 1.89 g. $100 \mathrm{~g}-1$; teores de cinzas de $0,39 \mathrm{~g} .100 \mathrm{~g}-1$ e $0,57 \mathrm{~g} .100 \mathrm{~g}-1$; fibra bruta na ordem de 11,82 g.100g-1 e 28,27 g.100g-1, FDN de 21,14 g.100g-1 e 32,28 g.100g-1, FDA de 17,53 g.100g-1 e 30,45 g.100g-1, hemicelulose de 3,61 g.100g-1 e 1,83 g.100g-1 e fração glicídica de 14,86 g.100g-1 e 8,53 g.100g1. No que se refere ao valor calórico foram encontradas 211,52 Kcal.100g-1 na polpa e 25,92 Kcal.100g-1, na amêndoa. Os valores de acidez observados para a polpa e amêndoa foram de 1,48 e 3,26 g de ácido cítrico.100g-1 e pH de 5,40 e 5,12, respectivamente. Para sólidos solúveis totais e açúcares totais os valores encontrados foram de 4,2 g.100g1 e 18,54 g. $100 \mathrm{~g}-1$ na polpa e $1,98 \mathrm{~g} \cdot 100 \mathrm{~g}-1$ e $3,31 \mathrm{~g} .100 \mathrm{~g}-1$ na amêndoa. Com os dados obtidos podem-se considerar esses frutos hipercalóricos, com significativas quantidades de fibras, proteínas e lipídeos, propiciando sua inclusão em dietas com alta densidade energética.

Palavras-chave: Composição Centesimal. Bacaba. Alimentos regionais.

\section{CENTESIMAL COMPOSITION AND PHYSICOCHEMICAL ASPECTS OF THE BACABA FRUITS (OENOCARPUS DISTICHUS MART.)}

\section{ABSTRACT}

The native fruits of Brazilian Cerrado, such as the bacaba (Oenocarpus distichus Mart.), have been appreciated for their exotic taste, however the nutritional aspects of bacaba are still yet little known. Thus, this study analyzed the quality parameters, physical chemical aspect and centesimal composition of the pulp and the almond of the bacaba fruit. The pulp and the almond of $O$. distichus Mart. presented 
respectively humidity of $53,72 \mathrm{~g} .100 \mathrm{~g}-{ }^{-1}$ and $62,73 \mathrm{~g} .100 \mathrm{~g}-{ }^{-1}$, ethereal extract $15,21 \mathrm{~g} \cdot 100 \mathrm{~g}^{-1}$ and $0,20 \mathrm{~g} \cdot 100 \mathrm{~g}^{-1}$, protein 3,8 g. $100 \mathrm{~g}^{-1}$ and $1.89 \mathrm{~g} \cdot 100 \mathrm{~g}^{-1}$, embers $0,39 \mathrm{~g}^{1} 100 \mathrm{~g}^{-1}$ and $0,57 \mathrm{~g}$.

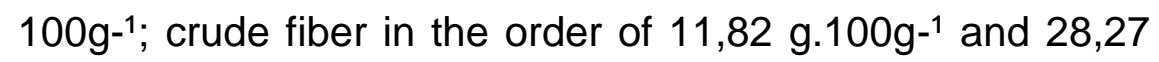
g. $100 \mathrm{~g}-{ }^{-1}$, NDF of $21,14 \mathrm{~g} .100 \mathrm{~g}-{ }^{-1}$ and $32,28 \mathrm{~g} .100 \mathrm{~g}-{ }^{-1}$, ADF of $17,53 \mathrm{~g} \cdot 100 \mathrm{~g}^{-1}$ and $30,45 \mathrm{~g} \cdot 100 \mathrm{~g}-1$, hemicellulose of 3,61 g. $100 \mathrm{~g}^{-1}$ and $1,83 \mathrm{~g} .100 \mathrm{~g}-1$, glucidic fraction of $14,86 \mathrm{~g} .100 \mathrm{~g}-1$ and $8,53 \mathrm{~g} \cdot 100 \mathrm{~g}^{-1}$. In relation to the caloric value were found $211,52 \mathrm{Kcal}^{1} 100 \mathrm{~g}^{-1}$ in the pulp and $25,92 \mathrm{Kcal}^{1} 100 \mathrm{~g}^{-1}$ in the almond. The acidity levels observed in the pulp and almond were 1,48 and $3,26 \mathrm{~g}$ of citric acid. $100 \mathrm{~g}{ }^{-1}$ and $\mathrm{pH}$ of 5,40 and 5,12 respectively. As for the soluble solids totals and sugar totals, the value found were $4,2 \mathrm{~g} \cdot 100 \mathrm{~g}^{-1}$ and $18,54 \mathrm{~g} \cdot 100 \mathrm{~g}^{-1}$

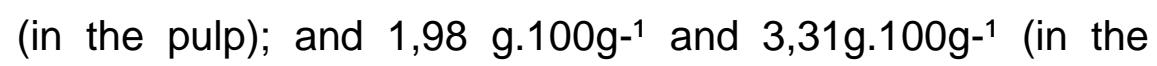
almond). With these data the fruits can be considered hypercaloric, containing significant quantities of fiber, protein and lipids which provides their inclusion in diets with high energetic density.

Key Words: Centesimal Composition. Bacaba. Regional food. 


\section{INTRODUÇÃO}

A família Arecaceae é constituída por palmeiras de grande importância para o homem, pela variedade de produtos que fornecem. Dentre essas espécies pode-se citar a bacaba-de-leque

(Oenocarpus distichus Mart.), muito prevalente na região Norte do Brasil, da qual se aproveitam todas as partes da planta, sendo usada na culinária, artesanato e paisagismo (PESCE, 2009). Essa palmeira é monocaule, tem porte arbóreo e folhas dísticas (ROCHA, 2009), se destacando por apresentar inegável potencial socioeconômico às populações locais, seja para a obtenção da bebida bacaba ou do azeite, similar ao de oliva.

O Brasil é o terceiro maior produtor de frutos $(6 \%$ da produção mundial) (ANDRIGUETO et al., 2010). $A$ região do cerrado se caracteriza por disponibilidade de frutos específicos, com elevado potencial econômico e nutricional, o que desperta o interesse por frutos do cerrado, tanto no mercado nacional, como no internacional.

Existem, na flora nativa brasileira e, em especial, na Região Meio-Norte do Brasil ou Nordeste Ocidental, algumas espécies ainda pouco conhecidas, mas que apresentam potencialidades para o mercado de amêndoas. Dentre essas, podem ser mencionadas o chichá (Sterculiastriata St. Hill. et Naud), a sapucaia (Lecythispisonis Camb.) e a castanhado-gurguéia (Dipteryxla cunifera Ducke) (ARAÚJO, 1997), todas conhecidas e utilizadas pelas populações locais.

Em geral, as amêndoas são ricas em proteínas e muito ricas em lipídios, não possuem colesterol, são boas fontes de fibras e possuem quantidades razoáveis de tiamina, riboflavina, niacina e ácidos graxos insaturados, em especial o ácido graxo oléico (n-9) (MEYER, 2013).

As características físicoquímicas dos frutos permitem avaliar o grau de maturação, determinar o ponto de colheita, definir formas de manuseio pós-colheita, acondicionamento apropriado, armazenamento e processamento para obtenção de seus derivados (CHITARRA; CHITARRA, 2005). Os frutos da maioria das palmeiras amazônicas são comestíveis, apresentam sabor característico e aspectos exóticos, o que os torna muito apreciáveis. 
Entretanto, a bacaba, mesmo sendo um fruto típico do Cerrado e da região Amazônica, possui valor nutricional e composição fitoquímica muito pouco estudadas.

Diante do exposto, o presente estudo teve como objetivo a avaliação da composição centesimal e dos aspectos físico-químicos da polpa e da

\section{METODOLOGIA}

\section{MATÉRIA-PRIMA E PREPAROS DAS AMOSTRAS}

Os frutos de bacaba da espécie Oenocarpus distichus Mart. foram colhidos no período de safra, entre os meses de Outubro e Novembro de 2014, em Taquaruçu Grande, BR 020, no entorno de Palmas- Tocantins e, em seguida, acondicionados em caixas térmicas e transportados para a Universidade Federal do Tocantins.

A espécie Oenocarpus distichus Mart. foi devidamente identificada, por meio da confecção de exsicata, que foi depositada no Herbário no Setor de Pesquisa Agropecuária da Fundação Universidade do Tocantins-UNITINS sob o número 5870.

Os frutos coletados foram selecionados visualmente quanto à amêndoa dos frutos de bacaba (Oenocarpus distichus Mart.), analisando a composição centesimal, as frações fibra detergente ácida, fibra detergente neutra e hemicelulose, o valor calórico, $\mathrm{o} \mathrm{pH}$, a acidez titulável total, os teores de sólidos solúveis totais, açúcares totais e a coloração.

dimensão (1,5 a 1,8cm de diâmetro), coloração, maturação e sanidade, isentos de insetos e injúrias. A matériaprima selecionada foi lavada em água corrente, em seguida em solução de cloro a 200 mg.L-1,durante 15 minutos, e novamente lavados em água corrente. Em seguida, a polpa com casca e a semente foram separadas manualmente. A polpa com casca foi macerada em almofariz e a sementes secas em estufas, até peso constante e, em seguida, trituradas em moinho de facas (Figura 1).

Por fim, a polpa foi acondicionada manualmente em frascos coletores de polietileno, com capacidade de $50 \mathrm{ml}$, armazenada e congelada a aproximadamente $20^{\circ} \mathrm{C}$ negativos, para posteriormente ser analisada. As sementes secas e 
trituradas foram armazenadas em sacos de polietileno, de $200 \mathrm{~g}$ e armazenadas em local seco e arejado, ao abrigo da luz. As análises físicas e químicas foram realizadas no Laboratório de Análise de Alimentos e no Laboratório de Tecnologia de Frutos e Hortaliças, na Universidade Federal do Tocantins.

Figura 1 - a. Fruto inteiro da bacaba; b. Polpa macerada; c. Amêndoas inteiras; d. Amêndoas

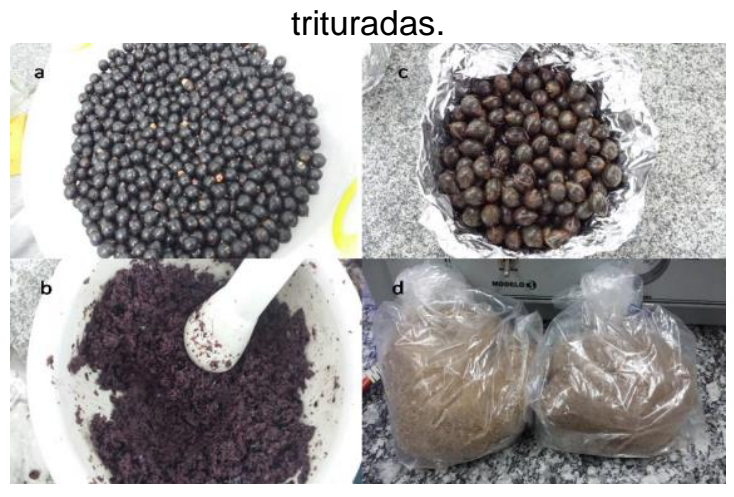

As análises físico-químicas e colorimétricas foram realizadas na polpa e na amêndoa do fruto da bacaba, totalizando sete repetições em triplicatas, para cada análise.

\section{DETERMINAÇÃO DA ACIDEZ TITULÁVEL TOTAL (ATT), POTENCIAL HIDROGENIÔNICO-PH, SÓLIDOS SOLÚVEIS TOTAIS (SST), AÇÚCARES SOLÚVEIS TOTAIS (AST) E COR INSTRUMENTAL}

A acidez titulável total e $\mathrm{opH}$ foram determinados de acordo com a técnica da Association of Official Agricultural Chemists - AOAC (1992). A determinação de sólidos solúveis totais foi realizada utilizando-se um refratômetro digital, da marca Atago, com escala entre 0 e $100 \stackrel{\circ}{\circ}$ Brix. Tanto a polpa como a semente foram diluídas em água destilada, em uma proporção de 1:1. Os resultados expressos em percentual (AOAC, 1992). Os açúcares solúveis totais foram determinados pelo método de Antrona (DISCHE, 1962). A leitura foi realizada em espectrofotômetro Beckman 640B. Os resultados foram expressos em percentual (g.100g-1 de polpa). A cor instrumental da polpa e da semente foi determinada diretamente, usando colorímetro digital Chroma Meter CR400 (Konica Minolta Sensing, Inc, Japão), empregando iluminante D65 e geometria $45 / 0$, e os valores de cor foram expressos no sistema CIELAB pelas coordenadas $L^{*}, a^{*}, b^{*}, H^{*}$ e $C^{*}$ (ZHANG et al., 2008). 
DETERMINAÇÃO DA UMIDADE, EXTRATO ETÉREO, CINZAS, PROTEÍNA BRUTA, FIBRA BRUTA, TEOR DE FIBRA DETERGENTE NEUTRO - FDN, FIBRA DETERGENTE ÁCIDA - FDA E HEMICELULOSE

A determinação de umidade, cinzas, proteína e fibra bruta foram determinadas pela AOAC (2005). Para o extrato etéreo foi utilizado o método de extração contínua em aparelho de "Soxhlet", utilizando como solvente o hexano (INSTITUTO ADOLFO LUTZ, 2008). O teor de fibra detergente neutro (FDN) e de fibra detergente ácido (FDA) foram determinados através da digestão em sistema automático, conforme BRASIL (1991). Para quantificação do teor de FDN e FDA foi utilizada a equação 1. A hemicelulose foi determinada pela diferença entres as frações de FDN e FDA (Brasil, 1991).

Equação 1:

$$
\begin{gathered}
\operatorname{FDN} \frac{(\mathrm{A}-\mathrm{B})}{\mathrm{C}} \times 100 \\
\mathrm{~A}=\text { Peso do cadinho + resíduo; }
\end{gathered}
$$

$\mathrm{B}=$ Peso do cadinho + cinzas $; \mathrm{C}=$ Peso

da amostra
DETERMINAÇÃO DA FRAÇÃO GLICÍDICA OU EXTRATO NÃO NITROGENADO

A fração glicídica foi obtida por diferença de $100 \%$ da soma dos demais componentes, segundo a equação: $F G=100-(U+E E+P+F B$ $+C)$, sendo: $F G=$ fração glicídica, $U=$ umidade; $\mathrm{EE}=$ extrato etéreo; $\mathrm{P}=$ proteína; $F B=$ fibra bruta; $C=$ cinzas (VILAS BOAS, 2006).

\section{DETERMINAÇÃO DO VALOR CALÓRICO}

O valor calórico dos alimentos é calculado a partir da quantidade de calorias (energia) que os nutrientes: carboidratos, lipídeos e proteínas podem ofertar, quando metabolizados no organismo.

O valor calórico total foi estimado conforme os fatores de conversão de Atwater: $4 \mathrm{Kcal} / \mathrm{g}$ de proteína; $4 \mathrm{Kcal} / \mathrm{g}$ de carboidrato e $9 \mathrm{Kcal} / \mathrm{g}$ de lipídeo, descritos por Osborne e Voogt (1978) e os resultados foram expressos em quilocalorias (Kcal). 
ANÁLISE ESTATÍSTICA

O delineamento foi inteiramente casualizado (DIC), com sete repetições, analisadas em triplicata.

As análises foram realizadas utilizando-se o procedimento MIXED do Statistical Analysis System (SAS, 2015) para avaliar o efeito da parte do fruto (polpa ou amêndoa) sobre as variáveisresposta, considerando-se as sete medidas repetidas, estas tratadas como um efeito aleatório. O nível de significância estatística adotado foi de $5 \%$.

\section{RESULTADOS E DISCUSSÃO}

A composição centesimal e o valor calórico da polpa e da amêndoa da bacaba estão apresentados na Tabela 1.

Tabela 1: Composição Centesimal e Valor Calórico da Polpa e da Amêndoa de Oenocarpus distichus

\begin{tabular}{lccc}
\multicolumn{4}{c}{ Mart. } \\
\hline Componentes $^{*}$ & Polpa & Amêndoa & Valor de p \\
\hline Umidade (g.100g-1) & $53,62 \pm 0,43$ & $60,73 \pm 0,30$ & $<0,0001$ \\
Extrato Etéreo (g.100g-1) & $15,21 \pm 0,16$ & $0,20 \pm 0,01$ & $<0,0001$ \\
Proteínas (g.100g-1) & $3,8 \pm 0,04$ & $1,89 \pm 0,02$ & $<0,0001$ \\
Cinzas (g.100g-1) & $0,39 \pm 0,00$ & $0,57 \pm 0,00$ & $<0,0001$ \\
Fração Glicídica (g.100g1) & $14,86 \pm 0,42$ & $8,53 \pm 0,42$ & $<0,0001$ \\
Fibra Bruta (g.100g-1) & $11,82 \pm 0,25$ & $28,27 \pm 0,46$ & $<0,0001$ \\
FDN (g.100g-1) & $21,14 \pm 0,41$ & $32,28 \pm 0,27$ & $<0,0001$ \\
FDA (g.100g-1) & $17,53 \pm 0,50$ & $30,45 \pm 0,36$ & $<0,0001$ \\
Hemicelulose (g.100g-1) & $3,61 \pm 0,11$ & $1,83 \pm 0,15$ & $<0,0001$ \\
Calorias (Kcal) & $211,52 \pm 2,66$ & $25,92 \pm 0,41$ & $<0,0001$ \\
\hline
\end{tabular}

*Teores médios \pm erro padrão da média, expressos em matéria integral Polpa e amêndoa diferiram entre si para todas as variáveis com $p<0,05$

FDN - Fibra Detergente Neutra FDA - Fibra Detergente Ácida

Tabela 2 - Valores médios* de pH, acidez titulável total (ATT), sólidos solúveis totais (SST), Açúcares Totais e relação SST/ATT da Polpa e da Amêndoa da Oenocarpus distichus Mart.

\begin{tabular}{llll}
\hline Componentes* & Polpa & Amêndoa & Valor de $\mathbf{p}$ \\
\hline Ph & $5,40 \pm 0,02$ & $5,12 \pm 0,01$ & $<0,0001$ \\
ATT & $1,48 \pm 0,09$ & $3,26 \pm 0,01$ & $<0,0001$ \\
SST & $4,2 \pm 0,06$ & $1,98 \pm 0,04$ & $<0,0001$ \\
Açúcares Totais & $18,54 \pm 0,29$ & $3,31 \pm 0,12$ & $<0,0001$ \\
SST/ATT & $3,02 \pm 0,20$ & $0,60 \pm 0,01$ & $<0,0001$ \\
\hline
\end{tabular}

*Teores médios \pm erro padrão da média

Polpa e amêndoa diferiram entre si para todas as variáveis com $p<0,0001$.

Pela análise estatística não houveram diferenças significativas entre as sete repetições da polpa quando comparadas entre si, o mesmo observou-se na amêndoa. Isso denota uma homogeneidade das amostras. 
Observou-se que as médias de todos os componentes nutritivos da polpa e da amêndoa diferiram significativamente entre si.

Os teores de umidade encontrados na polpa e na amêndoa de bacaba foram de $54 \%$ e $60 \%$, respectivamente, sendo que estatisticamente diferiram ente si $(p<0,0001)$ e ficaram abaixo daqueles encontrados por Domingues et al. (2014), em que a polpa apresentou $88,60 \%$, entretanto, os autores usaram polpa diluída em água na proporção de $1: 1$, o que possivelmente justifica a diferença de resultados. Canuto et al. (2010) e Silva (2013), encontraram para polpa de bacaba, procedente da região amazônica, teores de 87,6\% e $89,43 \%$, de umidade, respectivamente, também sendo diluídas em água. Cabe ressaltar que as coletas para 0 presente estudo foram realizadas no período de seca no Estado do Tocantins, o que fez com que a pluviosidade não interferisse nos resultados de umidade.

Estudo realizado por Alcântara (2015), em polpas de frutos da Oenocarpus bacaba Mart., demonstrou concentrações médias de umidade equivalentes a 54,21\%. Para a fração glicídica observou-se teor de 16,21\%; o teor de proteínas foi de 3,81\%; a fração lipídica correspondeu a $14,47 \%$ e o teor de cinzas foi de 3,79\%. Em relação ao teor de fibra bruta, a polpa apresentou $11,10 \%$. Os valores apresentados pelo autor assemelhamse aos encontrados para a polpa da bacaba no presente estudo.

Os valores de lipídeos encontrados na polpa e na amêndoa da bacaba foram de $15,21 \%$ e 0,20\%, respectivamente. Pode-se observar que a polpa possui teor de lipídeos muito superior ao da amêndoa $(p<0,0001)$ e esses resultados indicam que a polpa de bacaba é rica em lipídios, característica comum aos frutos das palmeiras, que estão incluídos no grupo das chamadas plantas oleaginosas.

Os frutos de açaí, que até então eram considerados ricos em lipídios, apresentam valores que variam de 1,5\% a 6,9\% (YUYAMA et al., 2004), valores estes muito inferiores aos encontrados na polpa da Oenorcarpus distichus Mart.

O teor médio de proteínas relatado na bacaba por Franco (1992) foi de $3,12 \%$, inferior ao encontrado neste trabalho. De modo geral, as frutas não são boas fontes de proteínas, apresentando, em média, 
$1 \%$ desse nutriente, sendo as cascas mais ricas que as partes comestíveis (GONDIM et al., 2005). Teores de 2,10\% de proteínas foram encontrados por Manhãese Sabaa- Srur (2011), em polpa de buriti, sendo o resultado também inferior à polpa do presente estudo. Porém, o presente estudo obteve maior teor proteico do que os encontrados por Finco et al. (2012b) para cagaita e murici $(0,98 \%$ e $1,89 \%$, respectivamente).

A O. distichus apresentou teor de fibra bruta na polpa igual a 11,82 g.100g-1 e na amêndoa, de 28,27 g.100g-1, diferindo estatisticamente entre si $(p<0,0001)$. A Portaria $n^{\circ} 27$, de 13 de janeiro de 1998 (BRASIL, 1998), estabelece que para que um alimento seja considerado de alto teor de fibras, ele deve apresentar no mínimo $6 \mathrm{~g}$. 100g-1 de fibras. Portanto, tanto a polpa como amêndoa de bacaba são excelentes fontes de fibras e seu consumo pode ser sugerido para populações que consomem quantidades insuficientes de fibras.

Fregonesi et al. (2010) e Alexandre et al. (2004), encontraram teores de fibra bruta significativos, porém menores que 0 da bacaba, na polpa de açaí $(4,57 \%$ e $4,37 \%$, respectivamente).
Os teores de FDN, FDA e hemiceluloses, diferiram significativamente $(p<0,0001)$, quando comparadas entre si, a polpa e a amêndoa.

Guimarães (2013) reportou valores de FDA de $51,1 \%$ e FDN de $0,4 \%$ em farinha de bacaca, a diferença entre os valores reportados é explicada pelo fato de que o autor utilizou o fruto inteiro enquanto que o presente estudo avaliou polpa e amêndoa separadamente. Entretanto, Sobreira (2011) encontrou valores de FDN e FDA em polpa $46,62 \%$ e $30,18 \%$ e amêndoa $45,96 \%$ e $31,01 \%$ da palmeira de macaúba, respectivamente, podendo observar que os valores de FDA assemelham-se ao resultado para amêndoa deste trabalho.

Townsend et al. (2000) encontraram para o açaí, valores para FDN e FDA de $93,9 \%$ e $64,9 \%$, respectivamente, sendo superiores aos encontrados na amêndoa de bacaba nesse estudo. Entretanto, os autores reportaram valores em matéria seca, o que possivelmente justifica a diferença de resultados já que os resultados do presente estudo foram expressos em matéria integral. Não foram encontrados trabalhos na literatura 
referente a dosagem de hemicelulose em bacaba.

Em relação aos teores de cinzas observou-se que polpa e amêndoa da bacaba, diferiram significativamente entre si $(p<0,0001)$, sendo o teor desse componente maior na amêndoa.

Os teores de cinzas encontrados por Nascimento et al. (2008), Alexandre et al. (2004) e Silva (2013) em polpa de açaí foram próximos aos da polpa da bacaba, estudada aqui $(0,39 \%)$, onde os autores detectaram, respectivamente, $0,41,0,45$ e $0,40 \%$ de cinzas.

Valores de $1,5 \%$ encontrados por Pinheiros et al. (2014) em polpa de bacaba proveniente do Pará estão superiores até mesmos aos encontrados na amêndoa de bacaba.

Guimarães (2013) obteve valores de $1,3 \%$ e $4,7 \%$ de cinzas em farinhas de bacaba e jerivá, respectivamente, superiores aos encontrados para a bacaba no presente estudo. Vale ressaltar que a diferença de valores de cinzas, entre as polpas das bacabas nos dois estudos, pode ser devida ao fato de que o autor citado obteve as dosagens de farinhas, enquanto nesse estudo as análises foram realizadas com polpa fresca.
Polpa e amêndoa, quando comparadas entre si, apresentaram teores de calorias estatisticamente $(p<0,0001)$ diferentes, sendo 0 teor calórico da polpa maior que o da amêndoa.

O valor calórico de $211 \mathrm{Kcal}$ por $100 \mathrm{~g}$, apresentado pela polpa de bacaba, mostra o alto valor energético do fruto. Franco (1999) apresenta valores energéticos de $212 \mathrm{Kcal}$ por $100 \mathrm{~g}$ para a bacaba, valor muito semelhante ao encontrado no presente estudo.

Segundo Manhães e Sabaa-Srur (2011), a polpa de buriti possui 166,36 Kcal e Domingues et al. (2014), encontraram 70,22 Kcal em frutos do bacabi (Oenocarpu smapora $\mathrm{H}$. Karsten). Apesar de serem todos frutos do mesmo gênero, os valores calóricos de buriti e bacabi são bem inferiores aos da O. distichus.

Os valores médios de $\mathrm{pH}$, acidez titulável total (ATT), sólidos solúveis totais (SST), açúcares totais e relação SST/ATT encontrados na polpa e na amêndoa da bacaba estão apresentados na Tabela 2.

Polpa e amêndoa diferiram significativamente entre si, para todas as características físico-químicas analisadas. 
A polpa e amêndoa da bacaba apresentaram $\mathrm{pH}$ próximos. Em estudo realizado por Canuto et al. (2010), a polpa de bacaba apresentou pH de 5,3, semelhantemente aos resultados do presente estudo. Esses valores são próximos aos reportados por Silva (2013), Fernandes et al. (2013) e Nascimento et al. (2008), em polpa de açaí, que foram de 4,9; 4,3 e 5,0 respectivamente. Valores de $\mathrm{pH}$ 5,33 foram encontrados por Alcântara (2015), em polpa de bacabas maduras.

Pode-se notar que a ATT da amêndoa da bacaba foi duas vezes maior que a da polpa, valores esses superiores aos encontrados por Guimarães (2013) na farinha de bacaba $(0,4 \%)$ e por Canuto et al. (2010) $(0,1 \%)$, em polpa de bacaba da Amazônia. Essa variação pode ser em decorrência das variações de ácidos orgânicos do solo, conforme observou Menezes et al. (2008).

Os valores médios de SST encontrados na polpa e amêndoa da Oenocarpus distichus Mart. foram bem inferiores aos reportados por Guimarães (2013), que apresentou $7,9 \%$ de SST em farinha de bacaba. Além disso, valores de SST inferiores $(2 \%)$ foram reportados por Canuto et al.
(2010) para polpa de bacaba, procedente da região amazônica.

Cruz (2008) encontrou na polpa de açaí, 5,1\% de SST, valor esse superior ao encontrado na bacaba. O teor de SST pode variar com a intensidade da chuva durante a safra, fatores climáticos, variedade, solo causando a diminuição de sólidos solúveis no produto final (SANTOS et al., 2002).

Alcântara (2015) relatou 4,67\% de SST em polpa de O. bacaba, valor esse semelhante ao encontrado para a espécie $O$. distichus, nesse estudo

Pode-se observar que o teor de açúcares e a relação SST/ATT na polpa são bem superiores aos da amêndoa, isso pode-se justificar pelo sabor mais adocicado que as polpas de frutos contém. Alcântara (2015), em suas análises encontrou 5,32\% de açúcares totais em seu experimento com polpa de bacaba, sendo esse valor bem inferior ao deste estudo.

A avaliação da cor instrumental no sistema CIELab foi utilizada para verificar a cor da polpa e da amêndoa da bacaba. Os resultados dos parâmetros de cor $\left(L^{*}, a^{*}, b^{*}, C^{*}\right.$ e $\left.H\right)$ são demonstrados na Tabela 3.

Observou-se que as médias dos componentes de coloração da polpa e 
da

amêndoa

diferiram

significativamente entre si, o que não ocorreu apenas para o componente $L^{*}$ e a coordenada $a^{*}$.

Pode-se observar que a polpa e a amêndoa de bacaba, utilizadas nesse estudo, apresentaram uma baixa luminosidade $\left(L^{*}\right)$, que foi 10,12 e 7,24 , respectivamente, característica de polpas de frutas de coloração escura como a do açaí e a da bacaba. Canuto et al. (2010), pesquisando polpa de bacaba, obtiveram para o parâmetro luminosidade, 26,8, valor superior ao encontrado no presente estudo, o que indica que a polpa utilizada por eles era mais clara. Valor de luminosidade $\left(\mathrm{L}^{*}\right)$ de 42,62 foi encontrado por Alcântara (2015) em polpa de bacaba, mostrando que a polpa estudada neste trabalho contém coloração mais escura que a do autor citado. Santiago (2010) observou que os frutos considerados ricos em antocianinas são intensamente coloridos, com suas cores variando principalmente entre o roxo e o preto.

As coordenadas $\mathrm{a}^{*}$ (vermelho) e b* (amarelo), para polpa e amêndoa de bacaba apresentaram valores de 3,59 e 4,35 e 1,75 e 8,57, respectivamente, podendo ser observado que o fruto se caracteriza por uma cor mais avermelhada.
Observou-se que valor de hue $\left(\mathrm{H}^{*}\right)$ para polpa foi de 31,61 sendo mais baixa que a amêndoa, que foi de 62,66, observando diferença estatística entre si com $p<0,0001$, o que nos permite dizer que a cor da polpa está mais próxima da região do vermelho-escuro ou roxo, o que possivelmente ocorre pelo alto teor de carotenoides e antocianinas presentes na polpa, conforme observou Rosso (2006). Valor para $\mathrm{H}^{*}$ de 47,08 foi encontrado por Alcântara (2015), na espécie Oenorcarpus bacaba Mart., sendo mais alto do que a para a espécie $O$. distichus do presente estudo.

Canuto et al. (2010), descreveram valor de $\mathrm{H}^{\star}$ de 56,0 para polpa de bacaba, superior ao encontrado nesse estudo. Sendo assim, a tonalidade da polpa utilizada no estudo deles era amareloavermelhada, já a tonalidade da bacaba do presente estudo foi avermelhada, essa diferença pode ter ocorrido pela variação do teor dos pigmentos existentes na polpa. No que se refere ao croma $\left(\mathrm{C}^{\star}\right)$, aqueles autores encontraram um valor de 20, sendo superior ao do presente experimento, o que indica que a polpa utilizada por eles apresentava coloração mais viva do que esta. $O$ 
presente estudo foi realizado com bacabas colhidas ne região do Tocantins, com características climáticas bem marcadas. Sugere-se a realização de futuros estudos com bacabas colhidas em outras regiões, o que pode evidenciar diferenças na composição.

Tabela 1: Valores médios* da Análise Colorimétrica da Polpa e da Amêndoa da Oenocarpus distichus

\begin{tabular}{lccc}
\multicolumn{3}{c}{ Mart. } \\
\hline Componentes $^{*}$ & Polpa & Amêndoa & Valor de $\mathrm{p}$ \\
\hline $\mathrm{L}^{*}$ & $10,12 \pm 2,13$ & $7,24 \pm 0,72$ & 0,1618 \\
$\mathrm{a}^{*}$ & $3,59 \pm 0,58$ & $4,35 \pm 0,18$ & 0,1774 \\
$\mathrm{~b}^{*}$ & $1,75 \pm 0,16$ & $8,57 \pm 0,42$ & $<0,0001$ \\
$\mathrm{C}^{*}$ & $4,08 \pm 0,46$ & $9,64 \pm 0,32$ & $<0,0001$ \\
$\mathrm{H}$ & $31,61 \pm 2,81$ & $62,66 \pm 1,41$ & $<0,0001$ \\
\hline
\end{tabular}

${ }^{\star}$ Teores médios \pm erro padrão da média

Polpa e amêndoa diferiram entre si para as variáveis $b^{*}, C^{*}$ e $H$ com $p<0,0001$.

\section{CONCLUSÕES}

Com base nos resultados, observou-se que tanto a polpa quanto a amêndoa são excelentes fontes de fibras, podendo ser utilizadas na elaboração de produtos ricos em fibras.
A polpa se mostrou hipercalórica possuindo altos teores de lipídeos, proteínas, carboidratos e valor energético, podendo ser incluídas em dietas que requerem alta densidade energética.

\section{REFERÊNCIAS}

ALCÂNTARA, E. M. Caracterização e Agregação de Valores à Bacaba (Oenocarpus bacaba Mart. ARECACEAE). 2015. 91 p. Tese (Doutorado em Ciência dos Alimentos)-Universidade Federal de Lavras, Lavras, 2015.

ALEXANDRE, D; CUNHA, R. L; HUBINGER, M. D. Conservação do açaí pela tecnologia de obstáculos. Ciência e Tecnologia de Alimentos, Campinas, v. 24, n. 1,p. 114- 119, 2004.

ANDRIGUETO, J. R.; NASSER, L. C. B.; TEIXEIRA, J. M. A. Produção integrada de frutas: conceito, histórico e a evolução para o sistema agropecuário de produção integrada -SAPI. Disponível em: <www. agricultura.gov.br $>$. Acesso em: mar. 2015. 
ARAÚJO, E. C. E. Chichá (Steculiastriata St. Hil. et Naud.): uma nova opção para os mercados nacional e internacional de nozes. Informativo SBF, Caçador, v.16, n.4, p.13-14, 1997.

ASSOCIATION OFF OFFICIAL AGRICULTURAL CHEMISTS. Official methods of analysis of Association of Official Agricultural Chemists.12th ed. Washington, 1992.1015 p.

ASSOCIATION OFF OFFICIAL AGRICULTURAL CHEMISTS. Official methods of analysis of Association of Official Agricultural Chemists.17th ed. Washington, 2005.1410 p.

BRASIL, Agência Nacional de Vigilância Sanitária (ANVISA). Portaria nํ27, de 13 de Janeiro de 1998. Brasília/DF, 1998.

BRASIL. MINISTÉRIO DA AGRICULTURA E REFORMA AGRÁRIA. Portaria ํㅜ 108, 4 setembro 1991. Aprova os Métodos Analíticos para Controle de Alimentos para uso Animal. Diário Oficial (República Federativa do Brasil, Brasília), p.19814, 17 set. 1991. Seção 1. Disponível em: <http://www.qualyfoco.com.br/arquivos_legislacao/ portaria_108_1991_metodos_analiticos_controle_alimentos_animal.pdf >. Acesso em 10 de setembro de 2015 .

CANUTO, G. A. B.; XAVIER, A. A. O.; NEVES, L. C.; BENASSI, M. T. Caracterização físico-química de polpas de frutos da Amazônia e sua correlação com a atividade antiradical livre. Revista Brasileira de Fruticultura, v. 32, n. 4, p. 1196-1205, dez. 2010.

CHITARRA, M. I. F \& CHITARRA, A. B. Pós-colheita de frutos e hortaliças: Fisiologia e manuseio. 2 ed. Lavras, UFLA. 785p. 2005.

CRUZ, A. P. Avaliação do efeito da extração e da microfiltração do açaí sobre sua composição e atividade antioxidante. 2008. 88 f. Dissertação (Mestrado em Ciências) - Universidade Federal do Rio de Janeiro, Rio de Janeiro - RJ. 2008.

DISCHE, Z. General color reactions. In: WHISTLER, R. L. \& WOLFRAM, M. L. Carbohydrate chemistry. New York, Academic Press, 1962. p. 277-512.

DOMINGUES, et al. Caracterização Físico-Química da Polpa de Bacabi (Oenocarpus mapora H. Karsten). Boletim de Pesquisa e Desenvolvimento. EMBRAPA. ISSN 1983-0483, fev. 2014.

FERNANDES, E. R.; BEZERRA, R. T. R.; COSTA, J. C. D. P. P.; ARÉVALO-PINEDO, A.; OLIVEIRA, E. S. R. Estudo da aceitabilidade do doce em corte à base de açaí (Euterpe oleracea). Revista Magistra, v. 25, p. 1678-1683, 2013. 
FINCO, F. D. B. A.; KAMMERER, D. R.; CARLE, R.; TSENG, W. H.; BÖSER, S.; GRAEVE, L. Antioxidant activity and characterization of phenolic compounds from bacaba (Oenocarpus bacaba Mart.) fruit by HPLC-DAD-MS. Journal of Agricultural and Food Chemistry, v. 60, n. 31, p. 7665-7673, Aug. 2012.

FRANCO, G. Tabela de composição química dos alimentos. Rio de Janeiro: Editora Atheneu, 1992. 307 p.

FREGONESI, B. M.; YOKOSAWA, C. E.; OKADA, I. A.; MASSAFERA, G.; COSTA, T. M. B.; PRADO, S. P. T. Polpa de açaí congelada: características nutricionais, físicoquímicas, microscópicas e avaliação da rotulagem. Revista do Instituto Adolfo Lutz, v. 69, n.3, São Paulo, 2010.

GONDIM, J. A. M. et al. Composição Centesimal e de Minerais em Cascas de Frutas. Ciência e Tecnologia de Alimentos, Campinas, v. 25, n. 4, p. 825-827, out./dez. 2005.

GUIMARÃES, A. C. G. Potencial funcional e nutricional de farinhas de jerivá (Syagrus romanzoffiana) e bacaba (Oenocarpus bacaba). 2013. 109 p. Dissertação (Mestrado em Ciência dos Alimentos)-Universidade Federal de Lavras, Lavras, 2013.

INSTITUTO ADOLFO LUTZ. Normas Analíticas do Instituto Adolfo Lutz. Métodos Químicos e Físicos para Análise de Alimentos. 1ª ed. São Paulo: IAL, 2008. 1020p.

MANHÃES L. R. T.; SABAA-SRUR A. U O. Centesimal composition and bioactive compounds in fruits of buriti collected in Pará. Revista Ciência Tecnologia de Alimentos, Campinas, v. 31, n. 4, 856-863, 2011.

MENEZES, E. M. S.; TORRES, A. T.; SRUR, A. U. S. Valor nutricional da polpa de açaí (Euterpe oleracea Mart) liofilizada. Acta Amazônica, v. 38, n. 2, Manaus, 2008.

MEYER, J. M. Teor e Composição de ácidos graxos de óleos de frutos de palmeiras nativas. 2013. Dissertação (Mestrado em Ciências - Botânica). Instituto de Biociências, Universidade de São Paulo - São Paulo/SP, 2013.

NASCIMENTO, R. J. S.; COURI, S.; ANTONIASSI, R.; FREITAS, S. P. Composição em ácidos graxos do óleo da polpa de açaí extraído com enzimas e com hexano. Revista Brasileira de Fruticultura, v. 30, n. 2, p. 498-502, Jaboticabal - SP, 2008.

OSBORNE, D. R.; VOOGT, P. The analysis in nutrient of foods. London: Academic, 1978. $158 \mathrm{p}$.

PESCE, C. Oleaginosas da Amazônia. 2. ed. rev. e atual. Belém: Núcleo de Estudos Agrários e Desenvolvimento Rural, 2009. 66 p. 
PINHEIRO, D. S.; MULLER, R. C. S.; SOUZA, E. C.; SILVA, A. S. Caracterização físico-química e quimiométrica de polpa de bacaba (oenocarpus bacaba) provenientes de dois municípios do estado do Pará. In: ENCONTRO DOS PROFISSIONAIS DE QUÍMICA DA AMAZÔNIA, 14., 2014, Manaus. Anais. 2014, p. 62-68.

ROCHA, A. E. A Importância das Palmeiras na Amazônia. Informativo do Museu Paraense Emílio Goeldi: Destaque Amazônia. Ano 25 N41, Novembro de 2009.

ROSSO, V. V. Composição de carotenóides e antocianinas em acerola. Estabilidade e atividade antioxidante em sistemas-modelo de extratos antociânicos de acerola e de açaí. Dissertação (Mestrado em Ciência de Alimentos). Faculdade de Engenharia de Alimentos - FEA. Unicamp, Campinas, SP, 2006.

SAS Institute Inc. SAS/STAT® 14.1 User's Guide. Cary, EUA: SAS Institute Inc, 2015.

SANTOS, E. M. Floristica Etnobotânica e Tipagem Fitoquímica de espécies medicinais de uso popular nos cerrados dos municípios de Caxias e Timon, Maranhão. Seminário de Iniciação Científica da UEMA, 2002.

SANTIAGO, M. C. P. A. Avaliação via Cromatografia Líquida de Alta Eficiência do efeito da microfiltração do suco da amora-preta (Rubus spp.) sobre a composição de suas antocianinas majoritárias. 2010, 93 f. Dissertação (Mestrado em Tecnologia de Processos Químicos e Bioquímicos) - Escola de Química, Universidade Federal do Rio de Janeiro, Rio de Janeiro, 2010.

SILVA, C. R. et al. Conteúdos de Celulose, Hemicelulose e Lignina em Dieta Hospitalar Hipocalórica. Revista Alimentos e Nutrição, São Paulo, v. 2, p. 65-71, 1990.

SILVA, P. P. M. Conservação de polpa de juçara (Euterpe edulis) submetida à radiação gama, pasteurização, liofilização e atomização. Tese (Doutorado em Ciências). Energia Nuclear na Agricultura e no Ambiente - Centro de Energia Nuclear na Agricultura da Universidade de São Paulo. Universidade de São Paulo. Piracicaba, 2013. 259p.

SOBREIRA, H. F. Resíduos do coco da macaúba em substituição parcial ao milho e farelo de soja em rações para vacas mestiças lactantes. 2011. $27 \mathrm{f}$. Dissertação (Mestrado em Zootecnia) - Universidade Federal de Viçosa, UFV, Viçosa, MG, 2011.

TOWNSEND, C. R.; COSTA, N. L.; SENGER, C. C. D. Características químicobromatológica do caroço de açaí. Boletim de Pesquisa e Desenvolvimento da EMBRAPA, n. 193, ago. 2000.

YUYAMA, L. K. O. et al. 2004. Açaí (Euterpe oleracea Mart.): Qual o seu potencial nutricional? Disponível em:www.ufpel.tche.br/sbfruti/anais_xvii_cbf/tecnologia_de_alimentos/264.htm. Acesso em:19/11/15. 
VILAS BOAS, E. V. B. Qualidade de alimentos vegetais. Lavras: UFLA/FAEPE, 2006. 68p.

ZHANG, Y.; HU, X. S.; CHEN, F. et al. Stability and color characteristics of PEF treated cyaniding-3-glicoside during storage. Food Chemistry, v. 106, p. 669-679, 2008.

Recebido em: 04/11/2016

Aprovado em: 19/12/2017 